\title{
Long-term behavior of the concentration of the minor constituents in the mesosphere - a model study
}

\author{
M. Grygalashvyly ${ }^{1}$, G. R. Sonnemann ${ }^{1,2}$, and P. Hartogh ${ }^{2}$ \\ ${ }^{1}$ Leibniz-Institute of Atmospheric Physics at the University Rostock in Kühlungsborn, Schloss-Str. 6, \\ 18225 Ostseebad Kühlungsborn, Germany \\ ${ }^{2}$ Max-Planck-Institute for Solar System Research, Max-Planck-Str. 2, 37191 Katlenburg-Lindau, Germany \\ Received: 12 October 2007 - Published in Atmos. Chem. Phys. Discuss.: 2 November 2007 \\ Revised: 30 March 2009 - Accepted: 30 March 2009 - Published: 27 April 2009
}

\begin{abstract}
We investigate the influence the rising concentrations of methane, nitrous oxide and carbon dioxide which have occurred since the pre-industrial era, have had on the chemistry of the mesosphere. For this investigation we use our global 3-D-model COMMA-IAP which was designed for the exploration of the MLT-region and in particular the extended mesopause region. Assumptions and approximations for the trends in the Lyman- $\alpha$ flux (needed for the water vapor dissociation rate), methane and the water vapor mixing ratio at the hygropause are necessary to accomplish this study. To approximate the solar Lyman- $\alpha$ flux back to the pre-industrial time, we derived a quadratic fit using the sunspot number record which extends back to 1749 and is the only solar proxy available for the Lyman- $\alpha$ flux prior to 1947 . We assume that methane increases with a constant growth rate from the pre-industrial era to the present. An unsolved problem for the model calculations consists of how the water vapor mixing ratio at the hygropause should be specified during this period. We assume that the hygropause was dryer during pre-industrial times than the present. As a consequence of methane oxidation, the model simulation indicates that the middle atmosphere has become more humid as a result of the rising methane concentration, but with some dependence on height and with a small time delay of few years. The solar influence on the water vapor mixing ratio is insignificant below about $80 \mathrm{~km}$ in summer high latitudes, but becomes increasingly more important above this altitude. The enhanced water vapor concentration increases
\end{abstract}

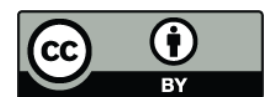

Correspondence to: M. Grygalashvyly (gryga@iap-kborn.de) the hydrogen radical concentration and reduces the mesospheric ozone. A second region of stronger ozone decrease is located in the vicinity of the stratopause. Increases in $\mathrm{CO}_{2}$ concentration enhance slightly the concentration of $\mathrm{CO}$ in the mesosphere. However, its influence upon the chemistry is small and its main effect is connected with a cooling of the upper atmosphere. The long-term behavior of water vapor is discussed in particular with respect to its impact on the NLC region.

\section{Introduction}

A trend refers to the tendency of a parameter to change during a sufficiently long time interval excluding the effects of all accidental (natural) and quasi cyclic variations. In this connection, trends in measured data are determined through statistical regression analysis and the statistical significance of the derived trend calculated. For this study, we use the available derived trends of a few minor constituents as input data for our model study. These trends are idealized since we assume that there has been an exponential increase in their value since the beginning of industrialization. Hence, for the calculations a constant growth rate derived from the estimated pre-industrial and current mixing ratios is used. The main goal of this paper is the reproduction of the observed water vapor increase in the middle atmosphere using the inferred trends of long-lived constituents such as methane $\left(\mathrm{CH}_{4}\right)$, nitrous oxide $\left(\mathrm{N}_{2} \mathrm{O}\right)$, and carbon dioxide $\left(\mathrm{CO}_{2}\right)$ and taking into account the derived variation of the solar Lyman$\alpha$ radiation which has a strong influence on the distribution of water vapor above the middle mesosphere. We investigate

Published by Copernicus Publications on behalf of the European Geosciences Union. 
the influence of these trends on the distribution of other chemically active minor constituents such as ozone $\left(\mathrm{O}_{3}\right)$ and hydroxyl $(\mathrm{OH})$. The model used in calculating the long term behavior based on these idealized inputs is a deterministic model. As a result, a statistical analysis of the calculated concentrations is unnecessary.

We use for calculations our global three-dimensional coupled dynamic-chemical transport model of the middle atmosphere COMMA-IAP (COlogne Model of the Middle Atmosphere of the Institute of Atmospheric Physics in Kühlungsborn). The model was particularly designed to investigate the spatio-temporal structure of phenomena in the MLT-region (mesosphere/lower thermosphere) and especially in the extended mesopause region. A more detailed description can be found in e.g. Berger (1994), Ebel et al. (1995), Sonnemann et al. (1998), Kremp et al. (1999), Berger and von Zahn (1999), Körner and Sonnemann (2001), and Hartogh et al. (2004).

We apply a new advective transport scheme developed by Walcek (2000) in the chemical transport model. This scheme is characterized by nearly zero numerical diffusion which is the most important precondition in order to correctly cope with the influence of the strong tidal wind components (Sonnemann and Grygalashvyly, 2005a). In addition, as described in Sect, 3, the dissociation rate of water vapor has been revised in accordance with the correction to the Lyman- $\alpha$ radiation recommended by Woods et al. (2000).

The main characteristics of COMMA-IAP are listed below. The grid point model extend from the ground up to the lower thermosphere $(0-150 \mathrm{~km} ; \mathrm{dz}=1.1 \mathrm{~km})$. The horizontal resolution amounts to $5^{\circ}$ in latitudinal and $5.625^{\circ}$ in longitudinal. The nonlinear (primitive) atmospheric equations are integrated in time steps of $225 \mathrm{~s}$. The radiative module takes into account the absorption of solar radiation by $\mathrm{O}_{2}, \mathrm{O}_{3}, \mathrm{H}_{2} \mathrm{O}$ and $\mathrm{CO}_{2}$ and infrared absorption and emission by $\mathrm{O}_{3}, \mathrm{H}_{2} \mathrm{O}$, $\mathrm{CO}_{2}$, NO and $\mathrm{O}$.

The Holton and Zhu (1984) gravity wave drag parameterization is employed as a source of mechanical dissipation. In this scheme, at each time step, the actual gravity wave momentum deposition due to a family of gravity waves with horizontal phase velocities of 5,25 and $50 \mathrm{~m} \mathrm{~s}^{-1}$ propagating simultaneously in four directions $\left(0^{\circ}, 90^{\circ}, 180^{\circ}, 270^{\circ}\right)$ is computed near critical and breaking levels. The gravity wave coefficient $\mathrm{K}_{Z Z}$ is used as the actual eddy diffusion parameter in order to calculate the vertical heat transport, the cooling due to the divergence of the vertical heat flux and the heating from dissipation of turbulent gravity wave energy (Prandtl number Pr=3). The gravity wave parameters are chosen in such a way that typical breaking altitudes occur in the extended mesopause region. As a result of the gravity wave momentum deposition on the mean flow, the model simulates realistic thermal structures such as the cold summer mesopause (with temperatures as small as $120 \mathrm{~K}$ ) and the two distinctive level structure of the mesopause (Berger and von Zahn, 1999). The resulting net heating rates drive the diabatic circulation in the model resulting in realistic wind systems (Kremp et al., 1999).

The chemical transport model (CTM) consists of a chemi$\mathrm{cal}$, a radiation and a transport code using the operator splitting method. The chemical code is based on the family concept introduced by Shimazaki (1985). Three families are subjected to transport. These are the odd hydrogen $(\mathrm{H}, \mathrm{OH}$, $\left.\mathrm{HO}_{2}\right)$, the odd oxygen $\left(\mathrm{O}, \mathrm{O}_{3}, \mathrm{O}\left({ }^{1} \mathrm{D}\right)\right)$ and the odd nitrogen (NO, $\left.\mathrm{NO}_{2}, \mathrm{~N}\left({ }^{4} \mathrm{~S}\right), \mathrm{N}\left({ }^{2} \mathrm{D}\right)\right)$ families. The hydrogen compounds $\mathrm{H}_{2}, \mathrm{H}_{2} \mathrm{O}, \mathrm{CH}_{4}$ and $\mathrm{H}_{2} \mathrm{O}_{2}$, the so-called even hydrogens, and other long-lived constituents are also subjected to transport. We use all relevant constituents and include all reactions of importance to the region of the atmosphere under consideration. The rate constants are taken according to Sander et al. (2006).

The radiation code that is used is described in Sonnemann and Fichtelmann (1989), Sonnemann et al. (1998) and Röth (1992). It is developed for thermospheric-mesospheric as well as for stratospheric models. The transport code incorporates both advective and turbulent and molecular diffusive transport. The eddy diffusion coefficient profile for the chemical transport is taken from Hocking (1990) and Lübken (1997).

The model does not operate interactively, i.e. the dynamical fields are used in the chemical transport model, but the chemical fields do not feed back to the dynamical part of the model. This drawback impacts in particular the feedback between $\mathrm{CO}_{2}$ increase and temperature decrease in the middle atmosphere (e.g. Berger and Dameris, 1993). The chemical calculations are based on dynamical fields representing the current state. On the other hand, as the model runs with the same dynamical fields, all changes to the chemical composition result from the change in the chemical input data mentioned above.

In addition, we consider how the chemical heating rate is influenced. We exclude here the investigation of its impact on the stratospheric chemistry with exception of the stratopause region. Special attention is paid to the seasonal and spatial range of the occurrence of noctilucent clouds (NLC) and polar mesospheric summer echoes (PMSE). In this paper we exclude the presentation and discussion of results associated with the $\mathrm{NO}_{\mathrm{x}}$-problem although the formation of $\mathrm{NO}_{\mathrm{x}}$ due to the oxidation of $\mathrm{N}_{2} \mathrm{O}$ by $\mathrm{O}\left({ }^{1} \mathrm{D}\right)$ is included in the model.

This paper is organized as follows. In the second section we deal with the trend data used for calculations. In the third section the problem of the derivation of the Lyman- $\alpha$ fluxes used in the model is discussed. The fourth section deals with the water vapor mixing ratio at the hygropause. The fifth section presents the main calculations and the results are discussed in section six. Finally, section seven summarizes the most important results. 


\section{Derived trend data}

Direct measurements of atmospheric minor constituents and the solar output are only available for the recent past. There are number of sources of indirect data and estimates of time series for the long-term period. Methane is the most important minor constituent influencing the increase of the water vapor mixing ratio in the middle atmosphere. Its so-called pre-industrial level has been estimated to be $0.75-0.85 \mathrm{ppmv}$ i.e. roughly half the present value (World Meteorological Organization, 1999). The present value is $1.75 \mathrm{ppmv}$ (Dlugokencky et al., 2003). The increase was essentially exponential except for the latest two decades when a decline of the growth rate was observed (Khalil et al., 1993; Dlugokencky et al., 2003). This seems to be zero for the last few years. Despite the decrease in the methane growth rate, we use a constant rate between 1880 and 2003 to achieve the increase in methane from 0.825 to $1.7 \mathrm{ppmv}$. In contrast to water vapor, as methane is not subjected to the freeze-dry process at the tropopause, the increases in methane concentration due to intensification of rice cultivation in marshland, stock-breeding, and additional anthropogenic sources can penetrate into the middle atmosphere.

The $\mathrm{N}_{2} \mathrm{O}$ concentration has also risen with the intensification of agriculture. We take into account its exponential increase from a pre-industrial level at the surface of $254 \mathrm{ppbv}$ to the current value of $320.2 \mathrm{ppbv}$ (IPCC, 2007). However, we do not consider the problem of rising $\mathrm{NO}_{\mathrm{x}}$ concentrations due to $\mathrm{N}_{2} \mathrm{O}$ oxidation because it requires more careful estimation of thermospheric sources, consideration of its formation by cosmic rays and sophisticated modeling of the stratosphere/troposphere exchange processes using a full stratospheric chemistry code.

The variation of the $\mathrm{CO}_{2}$ concentration is well known. There is generally an exponential growth with some variations. The growth rate mirrors events such as the world wars or the oil crises. The pre-industrial level at the ground is estimated to be $280 \mathrm{ppmv}$. The recent value is $375-380 \mathrm{ppmv}$ (Buchwitz et al., 2007). However, the impact of $\mathrm{CO}_{2}$ on chemistry is very limited.

\section{Long-term behavior of the Lyman- $\alpha$ radiation}

Lyman- $\alpha$ insolation, the most important radiation involved in the dissociation of water vapor above the middle mesosphere (roughly above $70 \mathrm{~km}$ ), varies strongly with solar activity. The absolute amount and the relative variation of Lyman- $\alpha$ radiation have recently been corrected (Woods et al., 2000). The old values used by the scientific community were based on measurements by Vidal-Madjar $(1975,1977)$, Vidal-Madjar and Phissamay (1980), and Simon (1981). The standard flux value for mean solar activity was $3 \times 10^{11}$ photons $\mathrm{cm}^{-2} \mathrm{~s}^{-1}$ and the variation from solar minimum to max- imum amounted to a factor of 2. The latest values, based on UARS measurements (Woods et al., 2000), are $4.65 \times 10^{11}$ photons $\mathrm{cm}^{-2} \mathrm{~s}^{-1}$ for the mean value and 3.7 and $5.6 \times 10^{11}$ photons $\mathrm{cm}^{-2} \mathrm{~s}^{-1}$ for the minimum and maximum, respectively. In the domain below about $75 \mathrm{~km}$, the radiation within the Schumann-Runge band system becomes increasingly important. The radiation varies by only a few percent and depends on wavelength. The longer the wavelength is, the smaller the variation. There has been an increase in solar activity since the time of the first observation of NLC in 1883 as the sunspot number or the geomagnetic activity verifies. However, direct Lyman- $\alpha$ measurements are only available for the last three solar cycles.

In order to reproduce temporal record of the solar output of the Lyman- $\alpha$ radiation, different solar proxies have been employed. Woods et al. (2000) used direct measurements from several satellites (such as the AE-E, SME and UARS) and filled the data gaps by employing solar proxies. The radiation record has been reconstructed back to 1947 using the solar $10.7 \mathrm{~cm}$ flux as proxy (available since that year). The only available direct or indirect solar proxies before 1947 are the sunspot numbers (available from 1749) and the geomagnetic activity (aa-index available since 1868). It is true that the geomagnetic activity varies with the solar activity as indicated by the sunspot number, but there is a time delay of about two years between sunspot number and geomagnetic activity. Surprisingly, this phase shift seems to agree with a delay of the occurrence rate of NLC (Gadsden, 1998; Thomas and Olivero, 2001). However, this assertion seems to be still under discussion. Thomas and Olivero (2001) used the sunspot number as proxy and calculated the Lyman- $\alpha$ flux on the basis of a quadratic fit. We also used the sunspot number as a proxy for the Lyman- $\alpha$ flux and quadratically fitted the sunspot number values to the Lyman- $\alpha$ flux values given by Woods et al. (2000). From this procedure we obtained a quadratic formula which can then be employed for the time range before 1947. Comparing the measured Lyman- $\alpha$ flux with the sunspot number, the correlation between both is weak at time scales of a few rotation periods of the sun or shorter, but strong at time scales in the order of a year. Therefore, we smooth the sunspot number over 11 months. For the Lyman- $\alpha$ flux we derive the expression

$$
\begin{aligned}
& \Phi(\mathrm{L} \alpha)=\left(3.396+1.71419 \times 10^{-2} \mathrm{~S}-1.68423 \times 10^{-5} \mathrm{~S}^{2}\right) \\
& \times 10^{11} \text { photons } \mathrm{cm}^{-2} \mathrm{~s}^{-1}
\end{aligned}
$$

S stands for the 11-month smoothed sunspot number. Figure 1 shows the result of this adjustment. The values vary between 3.5 and $5.8 \times 10^{11}$ photons $\mathrm{cm}^{-2} \mathrm{~s}^{-1}$ with exception of the strongest cycle which is at maximum in 1957. A general increase in the maximum (and mean) values takes place until the middle of the 20th century, but after that a decrease occurs. It is important to note that the minima display only 


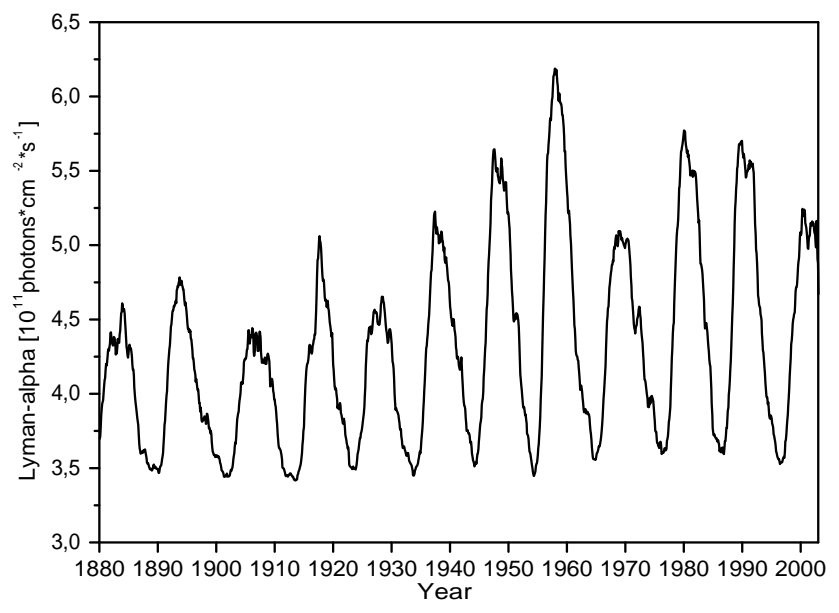

Fig. 1. Lyman- $\alpha$ flux reconstruction back to the time of first observations of NLC.

a weak increasing trend. Consequently we use these values for comparison of the change in composition of the minor constituents.

\section{Water vapor mixing ratio at the hygropause}

The hygropause separates the wet troposphere from the dry middle atmosphere. Water vapor is subjected to a freezedrying process and drops from some hundreds of ppmv in the troposphere to approximately 4 ppmv above the hygropause. Evidence for a changing hygropause was given by Forster and Shine (1999). A strong increase in stratospheric water vapor was found in the most recent past (Oldmans and Hofmann, 1995; Evans et al., 1998) of which only $40 \%$ could be explained by the methane increase (Forster and Shine, 1999). This is an indication that the pre-industrial hygropause was essentially dryer than now. The reason for this difference can be attributed to two factors.

Firstly, the globally averaged water vapor flux within the stratosphere is directed downward (Sonnemann and Körner, 2003). However, the flux of water vapor depends strongly on latitude and season. In the tropics upward moving air enters the stratosphere and dries at the cold high-altitude equatorial tropopause (hygropause). On the other hand, outside this region, stratospheric air associated with low pressure systems penetrates into the troposphere. Due to the methane oxidation in the stratosphere this air is more humid than the air penetrating into the stratosphere in the tropics. As mentioned above methane does not undergo the freeze-dry effect and consequently its lower boundary is determined by the methane concentration at the surface. Methane moves advectively and diffusively through the tropopause into the middle atmosphere and is oxidized to form water vapor there, creating a water vapor mixing ratio maximum close to the stratopause. An upward and downward directed water vapor flux results from this peak. This is a global mean picture which, of course, can differ locally or temporally.

The increase of the globally averaged water vapor mixing ratio with height in the stratosphere is characterized by a particular positive gradient. An interesting question is, whether the gradient depends directly on the magnitude of the water vapor maximum at the stratopause or not? If the water vapor mixing ratio at the hygropause is constant (actually an unrealistic picture), the vertical gradient of the water vapor mixing ratio becomes larger. If it is not, the hygropause becomes more humid in proportion to the water vapor increase at the stratopause.

Secondly, due to the increase in the concentrations of the different greenhouse gases, the troposphere has become warmer and, as a consequence, more humid. Water vapor is the most important greenhouse gas in the troposphere but it is triggered by the other greenhouse gases $\left(\mathrm{CO}_{2}, \mathrm{CH}_{4}\right.$, $\mathrm{N}_{2} \mathrm{O}, \mathrm{O}_{3}$, etc.) whose concentrations rise as a result of anthropogenic activity. Thus, the humidity at the hygropause should increase due to the change in tropospheric conditions. However, these simple arguments provide only a qualitative answer namely: the hygropause was dryer in pre-industrial times than the present but we cannot yet determine the true value.

For the model runs we use the water vapor mixing ratio above the hygropause as a lower boundary condition because we cannot simulate the complicated tropospheric water vapor content and the freeze-drying process with our model. In order to calculate the water vapor trend of the middle atmosphere we have to consider possible trends in the lower boundary conditions. As a lower boundary we apply a value which is $90 \%$ of the current one. This assumption is bases on the fact that the methane flux and consequently the humidity of the stratosphere were smaller in pre-industrial times. We are aware that this value is somewhat arbitrary.

\section{Results}

\subsection{Impacts due to the methane increase}

From a chemical point of view, the rising methane concentration is a very important anthropogenic increase of a minor constituent in the mesosphere. The total hydrogen content, meaning the number of hydrogen atoms anywhere bound in molecules, is a conservative quantity up to the height where molecular diffusion becomes effective. Methane is an efficient carrier of hydrogen. It is completely decomposed in the upper atmosphere. There is no effective formation process for methane in the atmosphere. Figure 2a displays the seasonal variation of the diurnally averaged water vapor mixing ratio at $67.5^{\circ} \mathrm{N}$ in 1890 - a solar minimum year - calculated by means of COMMA-IAP. This is also approximately the time of the eruption of the volcano Krakatoa in 1883. Before this event no NLC had been observed (Jesse, 1985; Schröder, 


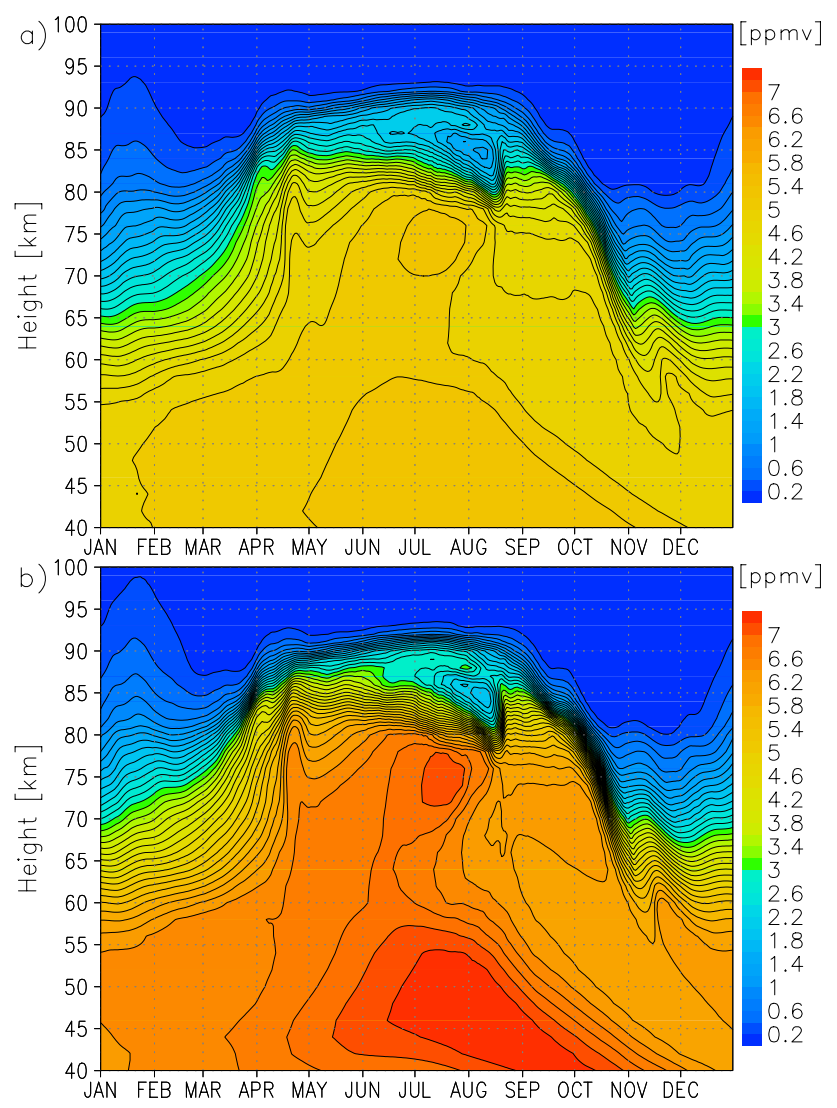

Fig. 2. Annual variation of the diurnally averaged water vapor mixing ratio at $67.5^{\circ} \mathrm{N}$ in 1890 (a) and in 1997 (b) calculated by means of COMMA-IAP.

1999). Figure $2 b$ exhibits the same state of affairs in 1997 , nearly the end of the time interval under consideration. Figure 3 shows the annual variation of a 7-day sliding mean of the water vapor mixing ratio at $\operatorname{ALOMAR}\left(69.29^{\circ} \mathrm{N}\right)$, Norway, measured by the microwave facility (Hartogh and Hartmann, 1990; Hartogh et al., 1991; Hartogh and Jarchow, 1995; Hartogh, 1997; Seele and Hartogh, 1999; Hartogh et al., 2004) in 1998 close to the year of solar minimum (the measurements at ALOMAR in 1997 were interrupted for a significant time interval). Comparing Figs. $2 b$ and $3-$ one can identify similar annual patterns and note that the mixing ratios are quantitatively reproduced in the lower and middle mesosphere. In the upper mesosphere the model values are slightly higher as was observed by HALOE (Nedoluha and Hartogh, 2000).

Figure 4 presents the annual variation of the relative deviation (rd) of a diurnally averaged water vapor mixing ratio (mr) between the solar activity minimum years 1997 and 1890 at $67.5^{\circ} \mathrm{N}$ calculated using the expression $\mathrm{rd}=\left(\mathrm{mr}_{1997^{-}}\right.$ $\left.\mathrm{mr}_{1890}\right) / \mathrm{mr}_{1890} \times 100[\%]$. We use these minimum years as reference years because the solar Lyman- $\alpha$ radiation changed only slightly from cycle to cycle during the minimum years, whereas during the maximum years the flux strongly de-

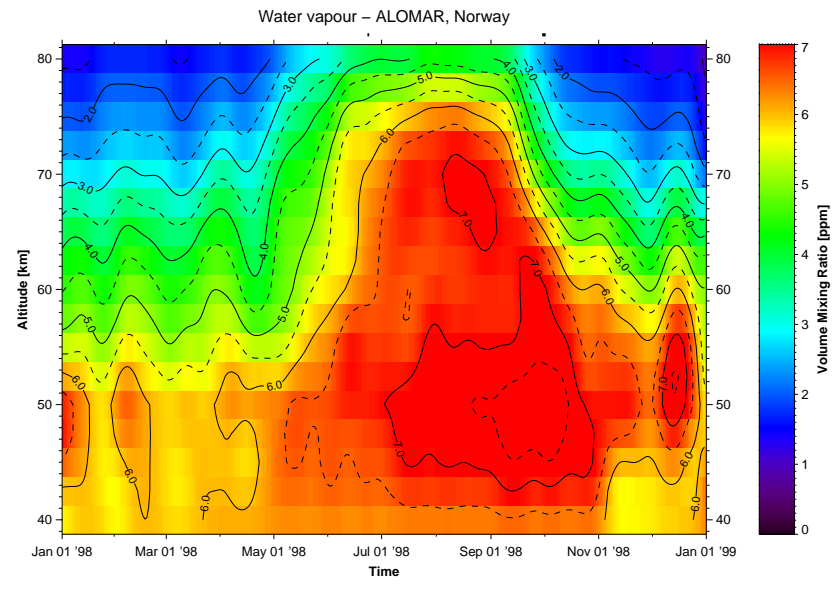

Fig. 3. Microwave measurements of water vapor in ALOMAR, Norway $\left(69.29^{\circ} \mathrm{N}\right)$, in 1998.

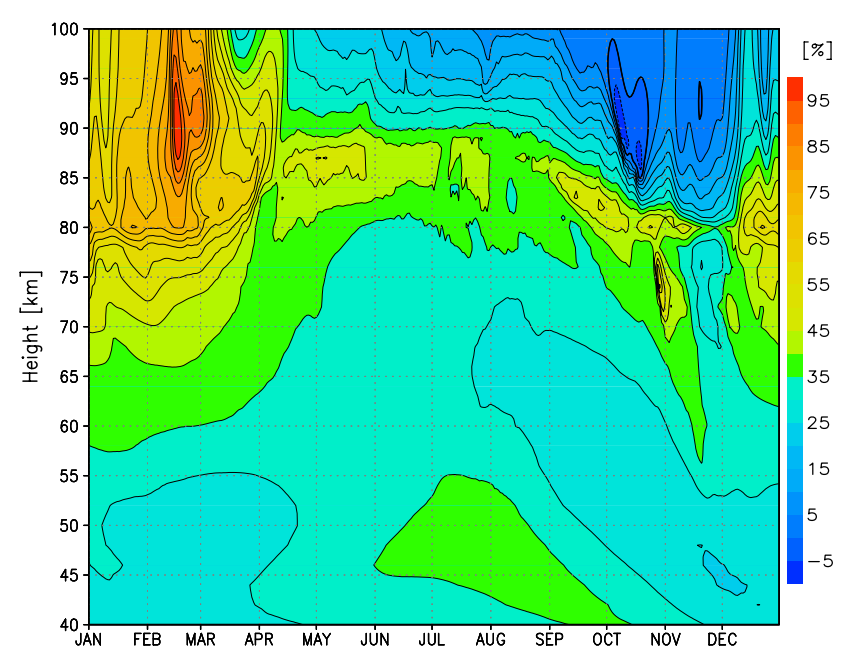

Fig. 4. Annual variation of the relative deviation of diurnally averaged water vapor between 1997 and 1890 at latitude of $67.5^{\circ} \mathrm{N}$.

pended on the individual cycle. Thus, for this times the change in the concentrations of the different constituents results predominantly from the increase of methane, carbon dioxide and nitrous oxide and not from an altered solar activity. Up to $85 \mathrm{~km}$, the change of the water vapor mixing ratio is generally positive. There is a region of slight decrease in water vapor mixing ratio above this border in September/October, whereas the increase is very strong in this domain from January until April. The absolute values are very small there so that small changes entail large relative variations. The main reason for this is likely the fact that the Lyman- $\alpha$ radiation also slightly increased over time and was somewhat higher in 1997 than in 1890. Another reason could be that the photochemical system responds in a nonlinear way which could influence the water vapor distribution in this region as we will discus later. 

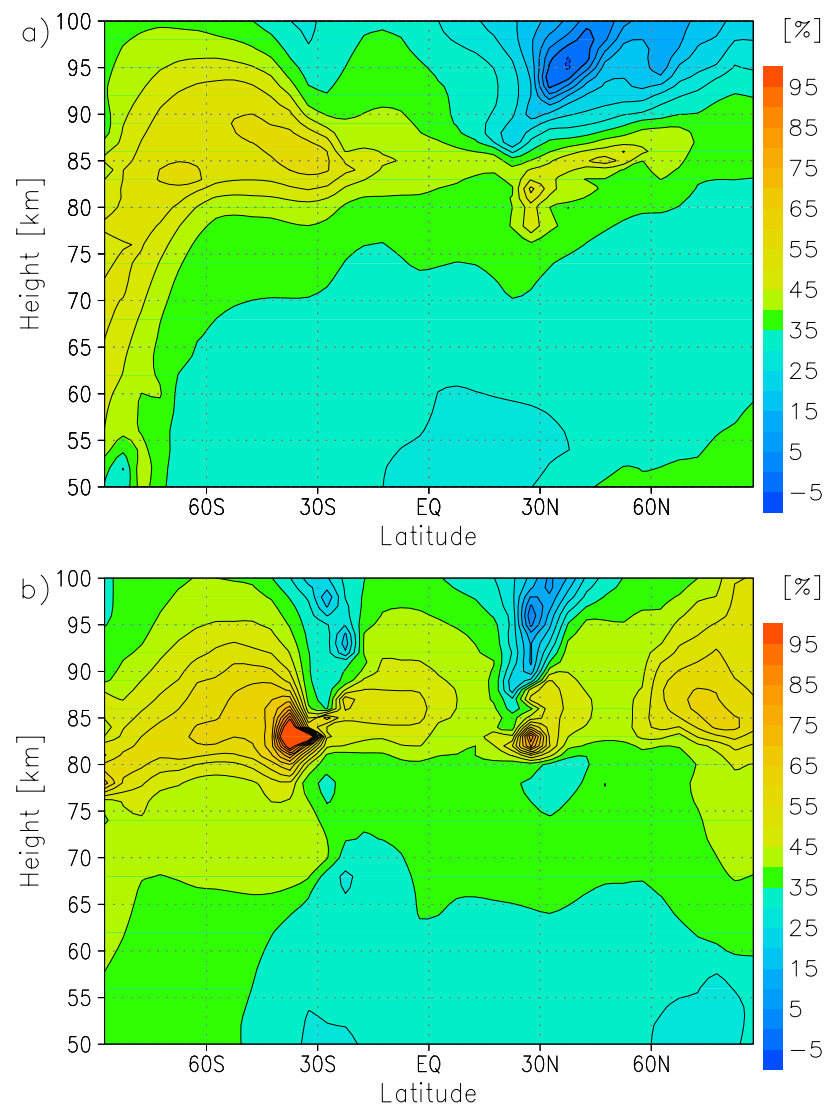

Fig. 5. Relative deviation of diurnally averaged water vapor mixing ratio between 1997 and 1890 in an altitude-latitude section for north summer solstice (1st of July, (a) and for spring equinox (1st of April, (b).

The relative deviations in a latitudinal section for northern summer solstice (1st July) and spring equinox (1st April) are shown in Fig. 5a and b, respectively. The figures demonstrate that the relative increase of middle atmospheric humidity depends on altitude, latitude and season. The strongest deviations occur in the mesopause region. In the region of NLCs and PMSEs at high latitudes during summertime which is marked by upward directed vertical winds, the relative deviations reach $35-45 \%$. A reason for the strong relative deviation in the mesopause region may be the autocatalytic water vapor production below $65 \mathrm{~km}$ (Sonnemann et al., 2005a) and the meridional transport. The more humid the atmosphere is, the more effective the process of autocatalytic water vapor production.

The diurnal variation of the water vapor mixing ratio is not significant below $80 \mathrm{~km}$ in high latitudes in summer, but above $80 \mathrm{~km}$, in the region of NLC and PMSE formation, it becomes stronger. The chemical lifetime amounts to some weeks at $80 \mathrm{~km}$ and below. Both the vertical and meridional gradients are not large enough for the tidal winds to markably modulate the diurnal amplitude. Figure 6a dis-

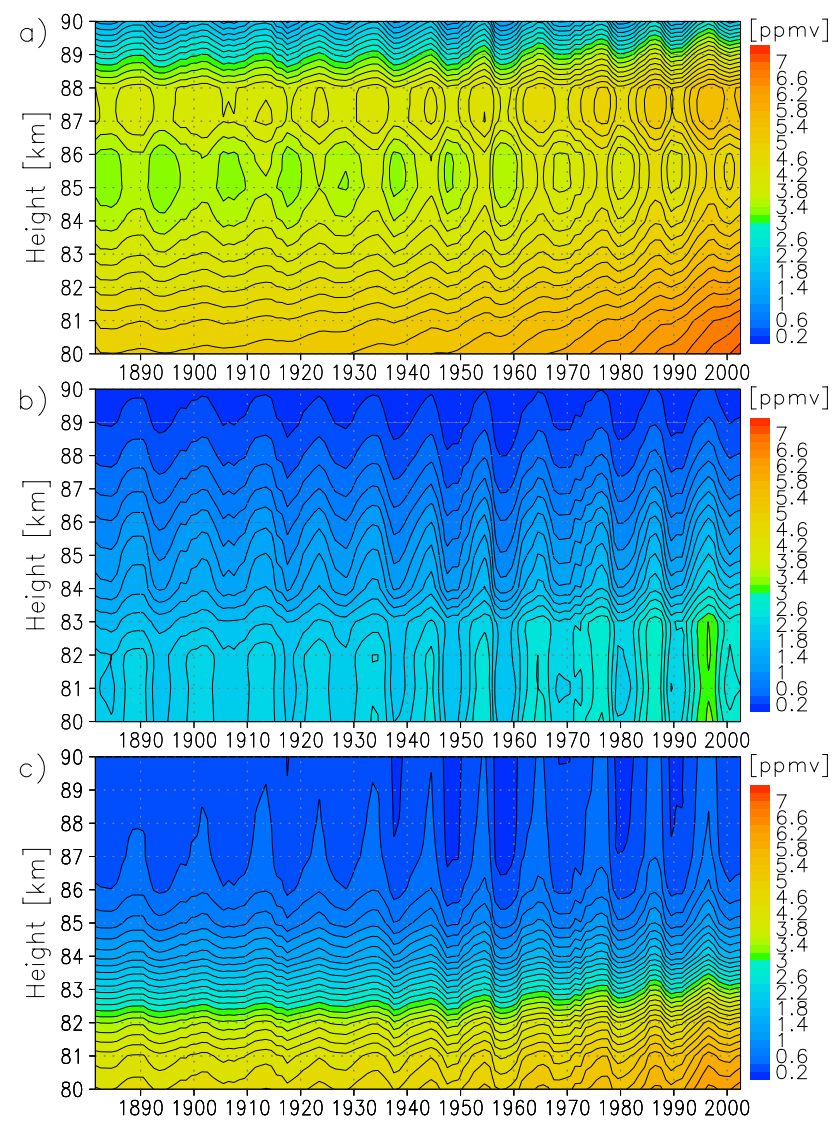

Fig. 6. Long-term behavior of the water vapor mixing ratio at midnight near summer solstice (1st of July) for $67.5^{\circ} \mathrm{N}(\mathbf{a}), 42.5^{\circ} \mathrm{N}(\mathbf{b})$ and $2.5^{\circ} \mathrm{N}(\mathbf{c})$.

plays the altitude-time section of the water vapor mixing ratio at $67.5^{\circ} \mathrm{N}$ near northern summer solstice (1st July) for midnight. Of note is the general increase of the mixing ratio at constant height. Above about $80 \mathrm{~km}$ the solar cycle is clearly mirrored. Figure $6 \mathrm{~b}$ and $\mathrm{c}$ show similar variations at middle and low latitude. One finds that the influence of the solar cycle penetrates deeper into the atmosphere at lower latitudes. This is due to the global vertical wind patterns. The upward directed vertical wind in high and moderate latitudes during the summer season lifts air that is not strongly influenced by the variations in solar activity from lower altitudes to heights where the variable Lyman- $\alpha$ radiation still penetrates. The comparison between the characteristic transport time and the characteristic time of photolysis is the decisive criterion for the amplitude of the variation with the solar cycle (Sonnemann and Grygalashvyly, 2005b). In contrast, the downward wind, which occurs during the winter season, advects air strongly influenced by the variable Lyman- $\alpha$ radiation to lower heights.

Within the NLC region the impact of the solar radiation is reduced, but the amplitude of the modulation of water vapor due to the solar cycle has a considerable gradient between 

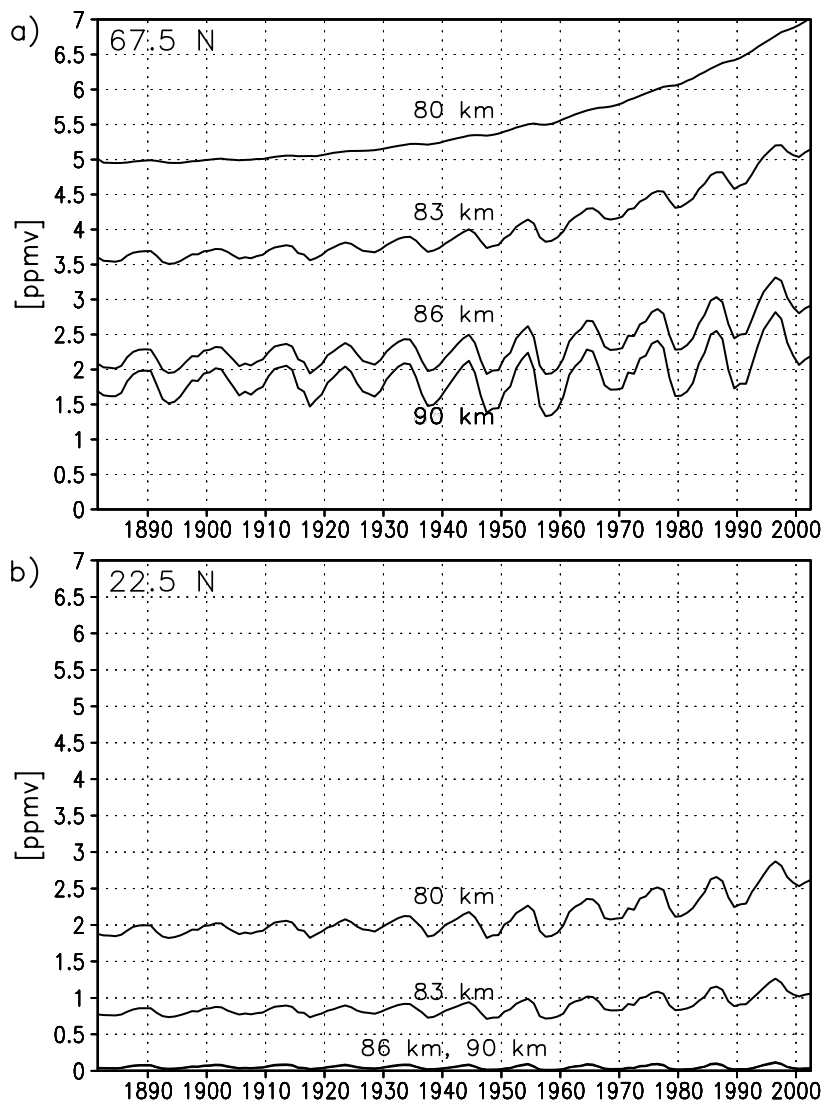

Fig. 7. Long-term behavior of diurnally averaged water vapor mixing ratio for summer solstice (1st of July) at $67.5^{\circ} \mathrm{N}$ (a) and $22.5^{\circ} \mathrm{N}$ (b).

80 and $90 \mathrm{~km}$. At $80 \mathrm{~km}$ the variation is small whereas at $90 \mathrm{~km}$ it is substantial. Although the condensation nuclei for NLC particles will be created at altitudes close to the temperature minimum at about 86 to $89 \mathrm{~km}$, the NLC particles sediment and grow in proportion to the surrounding water vapor mixing ratio. As a result the influence of the solar activity cycle on the NLC occurrence rate is dampened by the upward directed vertical wind. However, the temperature has the strongest influence on the growth of NLCs, but its variation with the solar cycle is not modeled.

Figure $7 \mathrm{a}$ and $\mathrm{b}$ display the increase of the water vapor mixing ratio at some selected mesospheric altitudes in high and low latitudes for summer solstice. The figures clearly show the latitudinal difference in response to the solar variation, particularly at $80 \mathrm{~km}$. Increasing water vapor concentrations are a source for greater hydrogen radical concentrations and these entail a stronger loss of the odd oxygen constituents: atomic oxygen and ozone. Figure $8 \mathrm{a}$ and b depict the relative deviation of the diurnally averaged ozone concentration in a latitudinal section for north summer solstice and equinox conditions. Generally, the ozone concentration decreases, with the exception of an area in high lat-
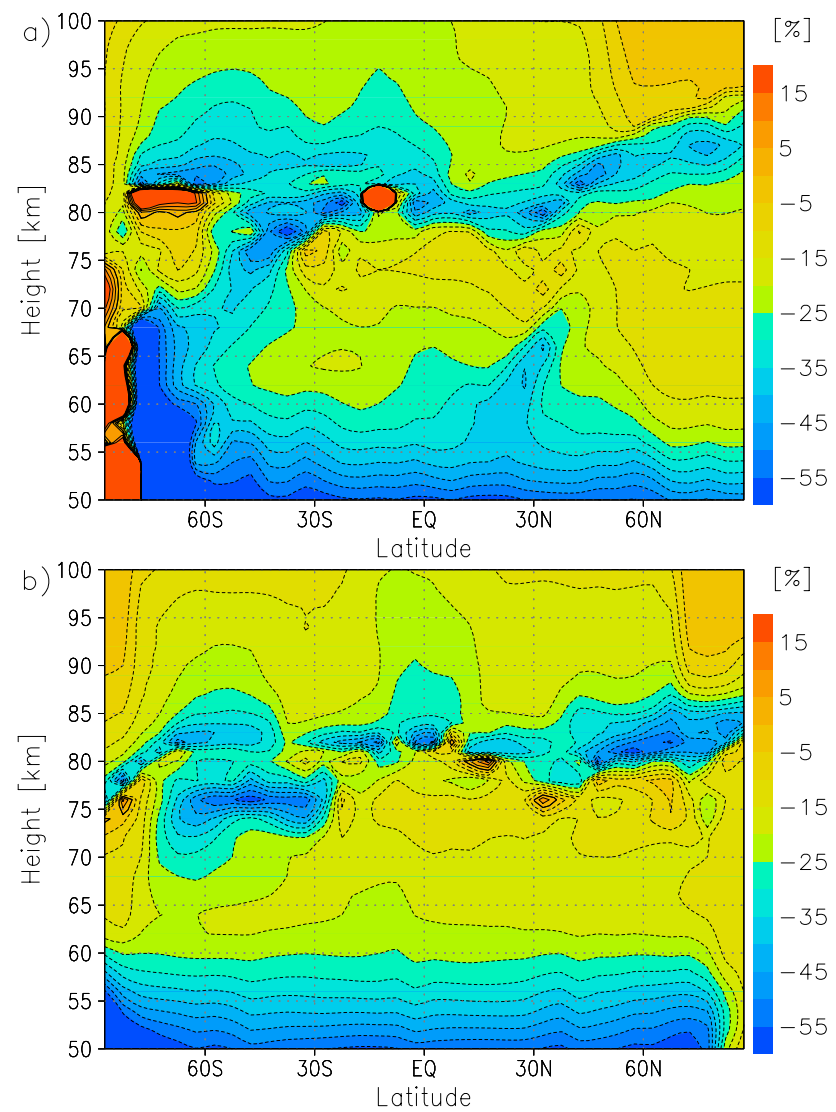

Fig. 8. Relative deviation of the diurnally averaged ozone mixing ratio in an altitude-latitude section for north summer solstice (1st of July, (a) and north spring equinox (1st of April, (b).

itudes around the mesopause. A further region of stronger ozone loss occurs in the vicinity of the stratopause, whereas the middle mesosphere is less strongly impacted. Atomic oxygen varies in a similar manner (not shown).

The chemical system of the mesosphere constitutes a nonlinear chemical oscillator driven by solar radiation (Sonnemann and Fichtelmann, 1987, 1997; Fichtelmann and Sonnemann, 1989). It responds nonlinearly when the characteristic chemical system time ranges in the order of one day the time of the diurnally periodic excitation by the radiation. This occurs in the mesopause region, and the nonlinear effects have been investigated in a number of publications by Sonnemann and co-workers and others (see Sonnemann and Grygalashvyly, 2005b and references therein). As the latitudinal sections in Fig. 8a and b indicate, different regions of ozone increase occur below the mesopause. This is due to the nonlinear response of the photochemical system. Because the integration time step in the CTM must be relatively large to allow trend calculations ( $15 \mathrm{~min}$ ) and the odd oxygen species are treated as a family, effects such as subharmonics or chaos cannot occur in our calculations because large time steps and the family concept suppress these phenomena 


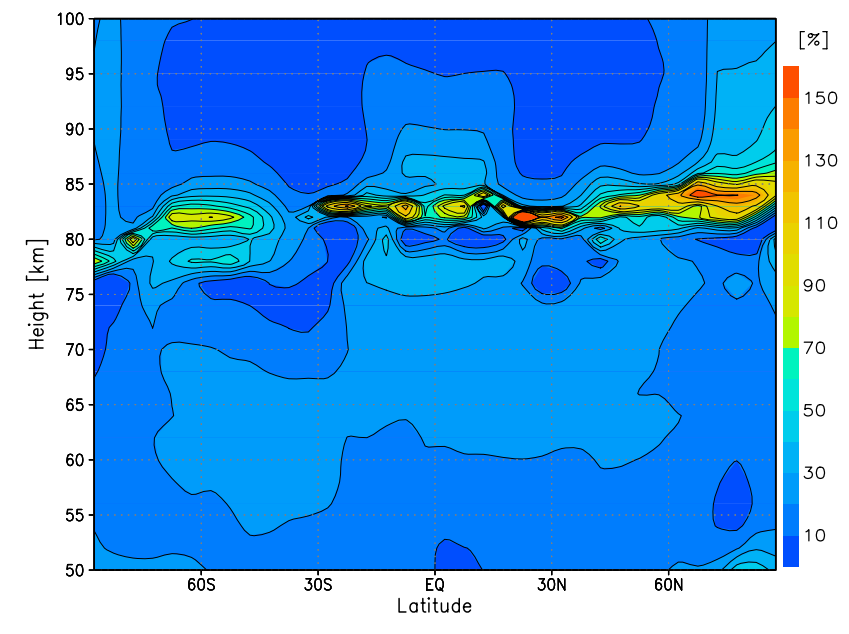

Fig. 9. Relative deviation of diurnally averaged hydroxyl mixing ratio in an altitude-latitude section for north spring equinox (1st of April).

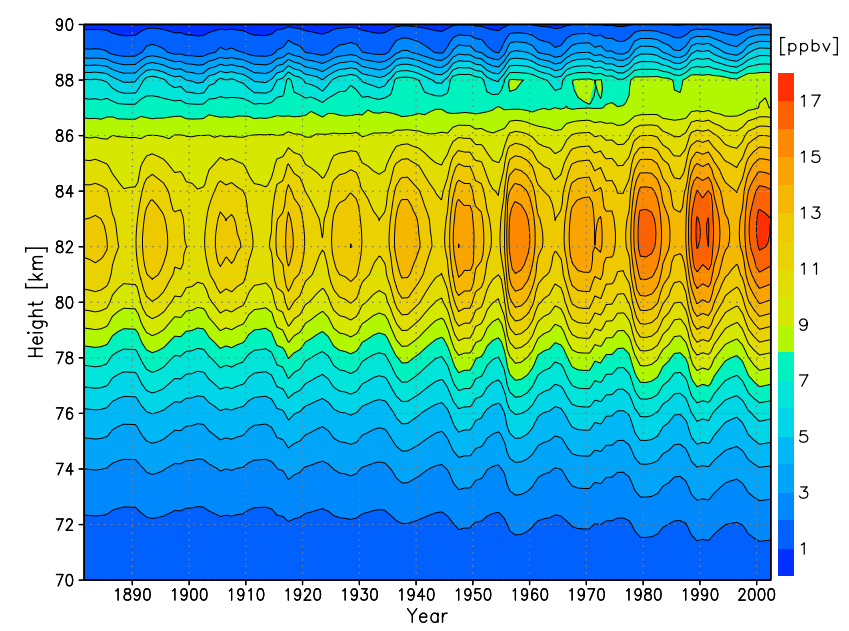

Fig. 10. Long-term behavior of the $\mathrm{OH}$-layer at $67.5^{\circ} \mathrm{N}$ for north summer solstice (1st July).

(see Sonnemann and Grygalashvyly, 2005b). But as Yang and Brasseur (1994) showed the photochemical system has a trigger solution under conditions associated with a hydrogen flux. Apparently the system tends to create bistable behavior in that domain.

Ozone decreases when the concentration of the hydrogen radicals increase. As an example, Fig. 9 depicts the relative deviation of the diurnally averaged hydroxyl mixing ratio associated with the conditions shown in Fig. 8b (1st April). The $\mathrm{OH}$-layer is located in the mesopause region. Figure 10 displays the increasing trend of diurnally averaged hydroxyl mixing ratio at $67.5^{\circ} \mathrm{N}$ for summer solstice. Note also the strong modulation by the solar cycle.

Chemical heating is a very important diabatic heating source which influences the thermal conditions under which NLC is formed. One might expect that a decline in the

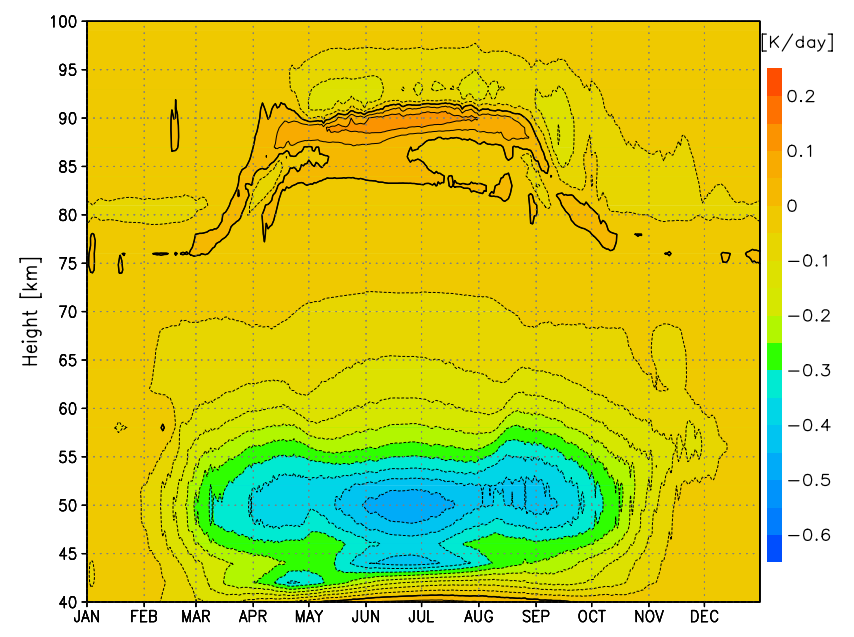

Fig. 11. Annual variation of absolute deviation of the chemical heating rate at $67.5^{\circ} \mathrm{N}$.

odd oxygen concentrations would also reduce the chemical heating rate. However the concentrations of the odd hydrogen constituents increase at the same time, which compensates this decrease in the model. The chemical heating is, in essence, determined by the stepwise recombination of atomic oxygen to molecular oxygen with the associated latent chemical energy deposited at the place of recombination. The latent chemical energy is transported downward from the thermosphere and created locally by the formation of $\mathrm{O}$ due to the dissociation of $\mathrm{O}_{2}$. These processes are not directly affected by the increasing humidity. The photolysis of water vapor is an insignificant part of the energetic balance. The stepwise recombination of atomic oxygen takes place via the formation of ozone and the formation of $\mathrm{OH}$ and $\mathrm{HO}_{2}$ within the odd oxygen destroying catalytic cycles. As a consequence, the height of recombination changes when the hydrogen radical concentration varies. This process depends on the vertical wind direction.

Figure 11 shows the absolute deviation of the diurnal chemical heating rate at $67.5^{\circ} \mathrm{N}$ between 1890 and 1997. The relative deviation of the chemical heating rate is less informative. The figure reveals two regions of strongest absolute changes both of which occur during summer. The first region is located at the summer mesopause (between 87 and $91 \mathrm{~km})$ and is characterized by the strongest increase of chemical heating rate. The most significant reactions for chemical heating in the region at $85-90 \mathrm{~km}$ are $\mathrm{OH}+\mathrm{O}, \mathrm{O}+\mathrm{HO}_{2}$ and $\mathrm{O}_{3}+\mathrm{H}$. Hence, this increase of the chemical heating rate is caused by the rising humidity in the mesopause region due to the enhanced odd-hydrogen production. However, this is damped by the decrease in odd oxygen concentrations which occurs at the same time as increasing odd hydrogen concentrations. Changes in the thermal regime feed back into the wind system and influence the chemical reaction rates. 


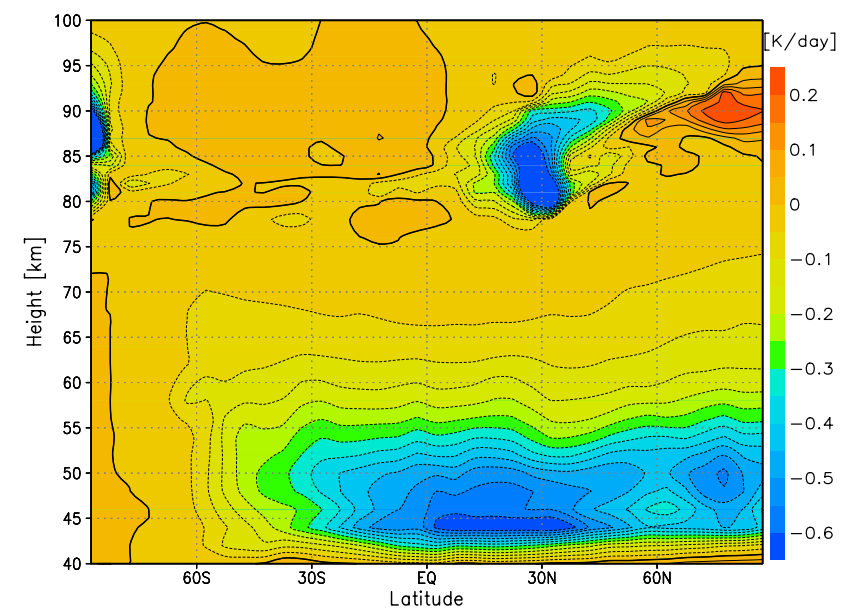

Fig. 12. Absolute deviation of the chemical heating rate for north summer solstice (1st July).

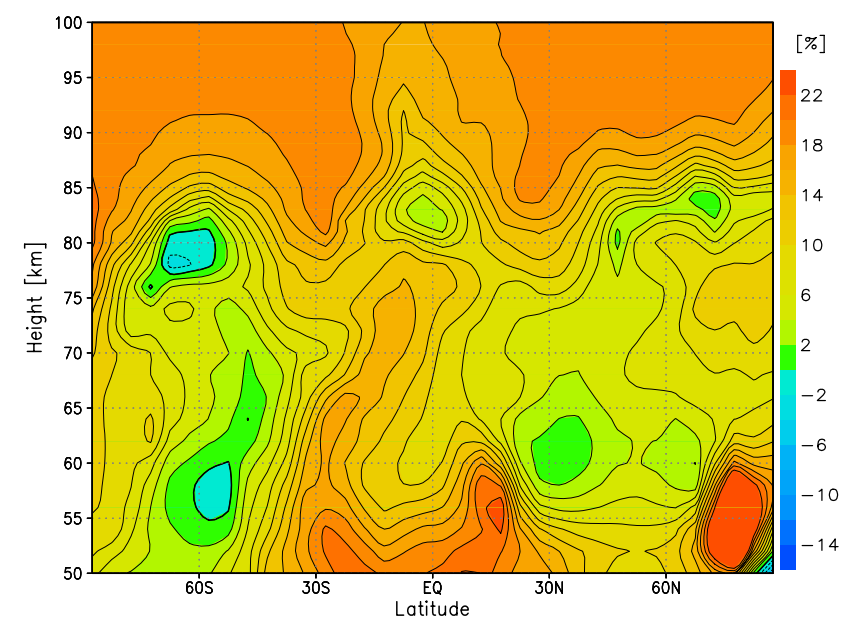

Fig. 13. Relative deviation of the diurnally averaged CO mixing ratio in a height-latitude section for the 1st of April.

The second region of strong absolute deviation is located close to the stratopause and has a negative sign. The main reaction involved in the production of chemical heating in the stratopause region is the three-body reaction $\mathrm{O}+\mathrm{O}_{2}+\mathrm{M}$. Its reaction rate increases with decreasing temperature. Consequently, this system results in negative feedback in both regions.

Figure 12 shows the latitudinal behavior of the absolute deviation of the diurnal chemical heating rate near north summer solstice (1st July) and illustrates the latitudinal extension of both regions. The trend of the chemical heating rate is negative from equator to approximately $50^{\circ} \mathrm{N}$ for all heights during the summer season. However its sign changes but from $50^{\circ} \mathrm{N}$ to the north pole in the mesopause region. This feature will be discussed below.

\subsection{Impacts due to the $\mathrm{CO}_{2}$ increase}

The most spectacular anthropogenic increase of a minor constituent is that of $\mathrm{CO}_{2}$. As mentioned earlier, we only briefly consider the change of the mesospheric chemistry due to the increase in $\mathrm{CO}_{2}$ and neglect its influence on the thermal regime of the middle atmosphere. Several studies have dealt with the impact of $\mathrm{CO}_{2}$ doubling on the thermal regime of the upper atmosphere (e.g., Berger and Dameris, 1993; Keating et al., 2000; Bremer and Berger, 2002), but none consider the response of the chemistry in the MLT region. Figure 13 shows the relative deviation of the $\mathrm{CO}$ concentration on 1st April. The increase of the $\mathrm{CO}$ mixing ratio depends not only on height, but also on latitude and season. The lifetime of $\mathrm{CO}$ is relatively long $\left(6.67 \times 10^{5} \mathrm{~s}\right.$ for $[\mathrm{OH}]=10^{7} \mathrm{~cm}^{-3}$ ). The impact on the composition of the hydrogen radicals is quite small and is not shown here, as there is only a radical conversion from $\mathrm{OH}$ to $\mathrm{H}$ and no radical loss occurs. However, the distribution of $\mathrm{OH}$ influences the mixing ratio of $\mathrm{CO}$. The figure displays a generally negative trend in the stratosphere. The reason is that the production of $\mathrm{OH}$ increases essentially more than that of $\mathrm{CO}$ in the stratosphere between 1890 and 1997. Thus, the loss process by $\mathrm{OH}$ is more effective than the increased formation of $\mathrm{CO}$ by the photolysis of $\mathrm{CO}_{2}$. In the mesosphere the picture is not uniform. Although $\mathrm{CO}$ increases in most regions, there are distinct domains with a small decreasing trend resulting from larger $\mathrm{OH}$-concentrations.

\section{Discussion}

One of the most interesting questions is, how much does the change in composition of atmospheric minor constituents influence the conditions for the formation of ice particles in the NLC region, i.e. conditions in the summer high latitudes. Temperature is the most important parameter controlling the creation of NLCs and PMSEs. It is assumed to decrease in the middle atmosphere due to the amplified radiative cooling associated with increases in $\mathrm{CO}_{2}$ concentration. However, cooling is not a homogeneous process which affects all altitudes in the same way. The curious finding is that the height of the NLC has not noticeably declined since the time of the first observation in 1883 (Jesse, 1885, 1891; von Zahn and Berger, 2003). The term "equithermal submesopause" was introduced by Lübken et al. (1996) to reflect the significant repeatability of the mean mesopause temperature over the past 40 years and the NLC height since its first observation. Recently, Lübken (2001) did not find a temperature trend in the mesosphere in high latitudes in summer. These unexpected findings are not simple to interpret. A cooling of the whole middle atmosphere should shift the levels of constant air density downward, as assumed in the publications on the change of the radio-wave reflection height using the 
technique of the phase-height measurement (e.g., Taubenheim, 1997; Bremer, 1997, 2001; Bremer and Berger, 2002).

In the mesopause region, the geometric height is crucial for determining the sign of the temperature change if the levels of constant air density decline. For a height above the mesopause (defined by the temperature minimum), the temperature increases due to its positive height gradient but this increase may be reduced by a cooling trend in its vicinity. Below the mesopause the temperature decreases due to the negative temperature gradient. The degree of water super-saturation is given by a specific Clausius-Clapeyron Equation. A drop of the levels of constant pressure also entails a decrease of the partial pressure of water vapor. At a constant height, this could be compensated for with the increasing humidity. Both processes, the decrease of temperature and the rise of humidity, should increase the occurrence rate of NLCs, as indeed has been observed since the time of their first observation (e.g., Gadsden, 1998). The question is why this did not result in a decrease in the height of their lower border, which is located below the mesopause. A possible explanation is that the positive trend in chemical heating rate at high latitudes near the mesopause (Figs. 11 and 12) partially compensates the cooling due to $\mathrm{CO}_{2}$ increase. These two processes produce opposite temperature trends and the result could be the absence of temperature trends in mesopause at high latitudes during the summer, as found by Lübken (2001). Thus, chemical heating can play a role in stabilizing the mesopause thermal structure and maintaining the "equithermal submesopause" at high latitudes in summer. In light of our calculations, at least for the mesopause, there is no contradiction between the measurements of Lübken (2001) and Hauchecorne et al. (1991), or Bremer and Berger (2002), who found negative trends of temperature in the mesosphere and the mesopause region at mid latitudes $\left(44^{\circ} \mathrm{N}\right.$ and $50.7^{\circ} \mathrm{N}$, respectively). Indeed, the trend in the chemical heating rate at mid latitudes is negative for all altitudes during the summer (Fig. 12) and cannot compensate for anthropogenic cooling.

This static picture does not completely explain this situation. Changes in the global polar anti-cyclone cause changes in the complete circulation. A weakening of the upward vertical wind which might occur as a result of the cooling of the underlying atmosphere could decrease the adiabatic cooling. Collision between $\mathrm{CO}_{2}$ and $\mathrm{O}$ are an efficient cooling process (Crutzen, 1970). A reduction of the atomic oxygen concentration makes this cooling process more inefficient. Earlier we noted that the chemical heating rate tends to increase in the polar summer mesopause region. Breaking gravity waves are a rather important diabatic heating source controlled by processes in the lower atmosphere which are subjected to climatic change. Typically, models are tuned using a somewhat arbitrary spectrum of gravity waves in order to obtain the observed zonal mean temperature distribution. In addition, the propagation of planetary waves and the occurrence of sudden stratospheric warming influence the thermal regime of the mesopause region. This enumeration of influences and associated discussion makes it clear that no simple explanation of these observations can be given. In addition, an increase in the occurrence rate of NLC with increasing humidity is expected (Thomas et al., 1989). In order to investigate the trend in the conditions in the NLC region, an interactive model is required which includes all essential processes.

The most important change of the chemically active minor constituents may involve $\mathrm{OH}$ in the $\mathrm{OH}$-layer. The airglow in the Meinel bands system is used by various authors to derive the temperature and to analyze gravity waves (Taylor and Garcia, 1995; Taylor, 1997; Taylor et al., 1998), but OH itself is also a subject of investigation (e.g., Offermann and Gerndt, 1990; Summers et al., 1996; Bittner et al., 2002). The Meinel bands airglow layer results primarily from the reaction $\mathrm{O}_{3}+\mathrm{H} \rightarrow \mathrm{OH}^{*}+\mathrm{O}_{2}$. The main loss process of the vibrationally excited states is quenching by other species. The chief loss of $\mathrm{OH}$ is the reaction with atomic oxygen. Since $\mathrm{O}$ decreases whereas the air density increases with decreasing height, the $\mathrm{OH}$-layer lies somewhat below the $\mathrm{OH}^{*}$-layer. With respect to the production term of $\mathrm{OH}^{*}, \mathrm{H}$ increases whereas $\mathrm{O}_{3}$ decreases with anthropogenic increase of water vapor reducing the airglow layer. Depending on season, latitude and vibrational number, the calculations show a $20-50 \%$ decrease in the $\mathrm{OH}^{*}$ concentration at the same layer altitude over the years. Thus, airglow measurements can be used for the study of anthropogenic changes in the mesopause region. In contrast, the $\mathrm{OH}-$ layer becomes more pronounced as a result of the decline of the loss term associated with reaction with O. Simultaneously, the height of the OH-layer increases.

The ozone decrease in the mesopause region was anticipated and attributed to an amplified catalytic cycle which includes $\mathrm{H}$ and $\mathrm{OH}$ as catalysts (Nicolet, 1970). In the upper mesosphere and mesopause region, the ozone destroying cycle involving atomic hydrogen acts as follows:

$$
\begin{aligned}
& \mathrm{O}_{3}+\mathrm{H} \rightarrow \mathrm{O}_{2}+\mathrm{OH} \\
& \mathrm{OH}+\mathrm{O} \rightarrow \mathrm{H}+\mathrm{O}_{2} \\
& \text { net : } \mathrm{O}+\mathrm{O}_{3} \rightarrow 2 \mathrm{O}_{2}
\end{aligned}
$$

This very effective cycle but its impact declined in the middle mesosphere as a result of the removal of $\mathrm{H}$ from the atmosphere through the three-body reaction $\mathrm{H}+\mathrm{O}_{2}+\mathrm{M} \rightarrow \mathrm{HO}_{2}+\mathrm{M}$ which depends quadratically on the air density.

Below the mesopause, the system tends to produce a trigger solution (Yang and Brasseur, 1994). However, it is impossible to give a definitive indication of what occurs on the basis of the relatively coarse integration procedure used here. An improved investigation is necessary. The reasons for the trigger solution in the vicinity of the ozone minimum at $80 \mathrm{~km}$ have been discussed in Hartogh et al. (2004). Yang and Brasseur (1994) proved its existence in a simplified model. 
The ozone decrease in the stratopause region is more important in terms of impact. Different groups have discussed the so-called ozone deficit problem (e.g., Eluszkiewicz and Allen, 1993; Siskind et al., 1995). This consists a systematic underestimation of the ozone concentration in the stratopause region (upper stratosphere-lower mesosphere) by the standard models. Crutzen et al. (1995) did not find a deficit. This finding indicates that ozone determining processes are not completely understood. A catalytic cycle including $\mathrm{H}, \mathrm{OH}$ and $\mathrm{HO}_{2}$ is responsible for the ozone decrease when the humidity increases.

The following cycle (Nicolet, 1970) becomes increasingly important from the middle mesosphere to the stratopause region:

$$
\begin{aligned}
& \mathrm{H}+\mathrm{O}_{2}+\mathrm{M} \rightarrow \mathrm{HO}_{2}+\mathrm{M} \\
& \mathrm{HO}_{2}+\mathrm{O} \rightarrow \mathrm{OH}+\mathrm{O}_{2} \\
& \mathrm{OH}+\mathrm{O} \rightarrow \mathrm{H}+\mathrm{O}_{2} \\
& \text { net }: \mathrm{O}+\mathrm{O} \rightarrow \mathrm{O}_{2}
\end{aligned}
$$

Atomic oxygen results from the dissociation of ozone so that this cycle reduces ozone. The relative effect is largest at or slightly above the stratopause. Due to the small reaction rate, the Chapman reaction $\mathrm{O}+\mathrm{O}_{3} \rightarrow 2 \mathrm{O}_{2}$ does not play a large role in the mesosphere. This process becomes more important below the stratopause, where the ozone concentration still strongly increases. The increasing humidity does not influence the reaction directly, but could be indirectly affected, if the concentration of $\mathrm{O}$ and the balance between the constituents, $\mathrm{O}$ and $\mathrm{O}_{3}$, is influenced by the hydrogen radicals.

This cycle, of course, acts in the whole atmosphere, but hydrogen radical concentrations toward the stratopause increase faster than atomic oxygen concentration decreases. Another fact must be taken into consideration: the positive feedback between ozone and the ozone dissociation rate. This effect was first implemented in calculations by Sonnemann et al. (2005b). The ozone dissociation rate is determined by the absorption of the radiation by ozone itself. This is the so-called self-shielding effect. An ozone decrease enhances the ozone dissociating radiation, which amplifies further ozone destruction lower in the domain at heights where the ozone dissociation rate decreases the most with decreasing height. This domain is approximately the altitude below $60 \mathrm{~km}$, and includes the extended stratopause region. Above this height a change of ozone has little effect on the downwelling radiation. This feedback is usually not considered in the models, but actual measurements do contain this effect.

\section{Summary}

We investigate the role the rising concentrations of methane, nitrous oxide and carbon dioxide since the pre-industrial era have on the chemistry of the mesosphere. For this investigation, we used our global 3-D-model COMMA-IAP which is designed for the exploration of the MLT-region and particularly the extended mesopause region. Using the sunspot number (available since 1749) as a solar proxy for the Lyman- $\alpha$ flux before 1947, we derived a quadratic fit and extrapolated the solar Lyman- $\alpha$ flux back to the pre-industrial time. The fit was based on Lyman- $\alpha$ flux values derived by Woods et al. (2000) which extend back to 1947. These extrapolated Lyman- $\alpha$ flux values were utilized in order to determine the water vapor dissociation rate. The analysis of the long-term behavior of water vapor is based on estimated methane trends since the pre-industrial era. This trend is modelled as an exponential increase in methane with a constant growth rate.

An unsolved and intricate problem for the model calculations consists of how the water vapor mixing ratio at the hygropause during the period of our study should be specified. We assumed that the hygropause was dryer during pre-industrial times than now and used a value $10 \%$ smaller than the current value as the lower boundary for the CTM. The methane oxidation results in a more humid middle atmosphere. Since the rising methane concentration yields two water vapor molecules per methane molecule. However the increase depends on height, season and solar activity. The solar influence on the water vapor mixing ratio due to the variation of Lyman- $\alpha$ radiation is insignificant below about $80 \mathrm{~km}$ in summer high latitudes, but it becomes increasingly more important above this altitude. The increasing water vapor concentration should impact the NLC occurrence rate, but the relations in the mesopause region are very intricate, so the exact change is difficult to determine.

The rising water vapor concentrations enhance the hydrogen radical concentrations and these reduce the mesospheric ozone, particularly in the mesopause region, due to the catalytic odd oxygen destruction processes. Another region of strong ozone decrease is located in the vicinity of the stratopause. A bistable chemical state around $80 \mathrm{~km}$ hints at a nonlinear response, but this effect should be investigated in more detail. Increasing hydrogen radical concentrations also influence the $\mathrm{OH}$-layer, which becomes more pronounced and the height of the maximum slightly increases. The change in the chemical heating rate was discussed. In the mesopause region the chemical heating rate increased, whereas it decreased in the stratopause region. The positive trend in the chemical heating rate at high latitude in the summer mesopause may play a role in stabilizing the temperature structure and may be one of the reasons of "equithermal submesopause".

Increasing $\mathrm{CO}_{2}$ concentrations somewhat increase the $\mathrm{CO}$ content of the mesosphere with the exception of some regions where $\mathrm{CO}$ slightly decreases. In these areas the increase of $\mathrm{OH}$ over-compensates for the rise in $\mathrm{CO}$. The trend analysis revealed a decrease of $\mathrm{CO}$ in the stratosphere as a result of a relatively strong growth in $\mathrm{OH}$ which is the 
only $\mathrm{CO}$ destroyer. The influence of $\mathrm{CO}$ upon the chemistry is very small. The impact of the $\mathrm{NO}_{\mathrm{x}}$ chemistry upon the odd oxygen-odd hydrogen system of the MLT region is also small. The main effect of increasing carbon dioxide is to cool the upper atmosphere. This cooling, and consequently the change of the dynamics and the chemical reaction rates, is not considered in the model. In this paper we also did not consider the change of $\mathrm{NO}_{\mathrm{x}}$ due to increasing $\mathrm{N}_{2} \mathrm{O}$ concentrations.

The model does not run interactively, so the annual variations of the dynamic fields did not change from year to year over the calculated period. Hence, all trends result from the chemistry and, to a small extent, from the variation of the Lyman- $\alpha$ radiation.

Acknowledgements. This work was supported by the Deutsche Forschungsgemeinschaft (DFG) grant So268/4.

Edited by: W. Ward

\section{References}

Berger, U.: Numerische Simulation klimatologischer Prozesse und thermische Gezeiten in der mittleren Atmosphäre, Thesis, Univ. Cologne, Germany, 1994.

Berger, U. and Dameris, M.: Cooling of the upper atmosphere due to $\mathrm{CO}_{2}$ increases: a model study, Ann. Geophys., 11, 809-819, 1993, http://www.ann-geophys.net/11/809/1993/.

Berger, U. and von Zahn, U.: The two-level structure of the mesopause: A model study, J. Geophys. Res., 104, 2208322093, 1999.

Bittner, M., Offermann, D., Graef, H.-H., Donner, M., and Hamilton, K.: An 18 year time series of $\mathrm{OH}$ rotational temperatures and middle atmosphere decadal variations, J. Atmos. Sol. Terr. Phys., 64, 1147-1166, 2002.

Bremer, J.: Long-term trends in the meso- and thermosphere, Adv. Space Res., 20, 2075-2083, 1997.

Bremer, J.: Trends in the thermosphere derived from global ionosonde observations, Adv. Space Res., 28, 997-1006, 2001.

Bremer, J. and Berger, U.: Mesospheric temperature trends derived from ground-based LF phase-height observations at midlatitudes: comparison with model simulations, J. Atmos. Sol. Terr. Phys., 64, 805-816, 2002.

Buchwitz, M., Schneising, O., Burrows, J. P., Bovensmann, H., Reuter, M., and Notholt, J.: First direct observation of the atmospheric $\mathrm{CO}_{2}$ year-to-year increase from space, Atmos. Chem Phys., 7, 4249-4256, 2007.

Crutzen, P. J.: Discussion of paper "Absorption and emission by carbon dioxide in the atmosphere" edited by Houghton, J. T., Q. J. Roy. Meteor. Soc., 96, 767, 1970.

Crutzen, P. J., Grooss, J.-U., Bruehl, C., Mueller, R., and Russel III, J. M.: A reevaluation of the ozone budget with HALOE UARS data: No evidence of the ozone deficit, Science, 268, 705-708, 1995.

Dlugokencky, E. J., Houweling, S., Bruhwiler, L., Masarie, K. A., Lang, P. M., Miller, J. B., and Tans, P. P.: Atmospheric methane levels off: Temporary pause or a new steady-state?, Geophys. Res. Lett., 30, 1992, doi:10,1029/2003GL018126, 2003.
Ebel, A., Berger, U., and Krueger, B. C.: Numerical simulations with COMMA, a global model of the middle atmosphere, SIMPO Newsletter, 12, 22-32, 1995.

Eluszkiewicz, J. and M. Allen, A global analysis of the ozone deficit in the upper stratosphere and lower mesosphere, J. Geophys. Res., 98, 1069-1082, 1993.

Evans, S. J., Toumi, R., Harries, J. E., Chipperfield, M. P., and Russel, J. M.: Trends in stratospheric humidity and the sensitivity of ozone to these trends, J. Geophys. Res., 103, 8715-8725, 1998.

Fichtelmann, B. and Sonnemann, G.: On the variation of ozone in the upper mesosphere and lower thermosphere: A comparison between theory and observation, Z. Meteorol., 39, 297-308, 1989.

Forster, P. M. de F., and Shine, K. P.: Stratospheric water vapour changes as a possible contributor to observed stratospheric cooling, Geophys. Res. Lett., 26, 3309-3312, 1999.

Gadsden, M.: The North-West Europe data on noctilucent clouds: A survey, J. Atmos. Terr. Phys., 60, 1163-1174, 1998.

Hartogh, P.: High resolution chirp transform spectrometer for middle atmospheric microwave sounding, in: Satellite Remote Sensing of Clouds and the Atmosphere II, edited by: Haigh, J. D., Proc. SPIE, 3220, 115-124, 1997.

Hartogh, P. and Hartmann, G. K.: A high resolution chirp transform spectrometer for microwave measurements, Meas. Sci. Technol., 1, 592-595, 1990.

Hartogh, P. and Jarchow, C.: Ground-based detection of middle atmospheric water vapour, in: Global Process Monitoring and Remote Sensing of the Ocean and Sea Ice, edited by: Deering, D. W. and Gudmandsen, P., Proc. SPIE, 2586, 188-195, 1995.

Hartogh, P., Hartmann, G. K., and Zimmermann, P.: Simultaneous water vapor and ozone measurements with millimeterwaves in the stratosphere and mesosphere, IEEE Catalog Number 91CH2971-0, 1, 227-230, 1991.

Hartogh, P., Jarchow, C., Sonnemann, G. R., and Grygalashvyly, M.: On the spatiotemporal behavior of ozone within the upper mesosphere/mesopause region under nearly polar night conditions, J. Geophys. Res., 109, D18303, doi:10.1029/2004JD004576, 2004.

Hauchecorne, A., Chanin, M.-L., and Keckhut, P.: Climatology and trends of the middle atmospheric temperature $(33-87 \mathrm{~km})$ as seen by Rayleigh Lidar over the south of France, J. Geophys. Res., 96, 15297-15309, 1991.

Hocking, W. K.: Turbulence in the region 80-120 km, Adv. Space Res., 10(12), 153-161, 1990.

Holton, J. R. and Zhu, X.: A further study of gravity wave induced drag and diffusion in the mesosphere, J. Atmos. Sci., 41, 12531267, 1984.

IPCC Climate Change 2007: The Physical Science Basis, Cambridge Univ. Press, Cambridge, UK and New York, NY, USA, 2007.

Jesse, O.: Auffallende Abenderscheinung am Himmel, Meteorol. Z., 2, 311-312, 1885.

Jesse, O.: Untersuchungen über die sogenannten leuchtenden Nachtwolken, Meteorol. Z., 8, 306-308, 1891.

Keating, G. M., Tolson, R. H., and Bradford, M. S.: Evidence of long-term global decline in the Earth's thermospheric density apparently related to anthropogenic effects, Geophys. Res. Lett., 27, 1523-1526, 2000.

Khalil, M. A. K., Rasmussen, R. A., and Moraes, F.: Atmospheric 
methane at Cap Meares: Analysis of a high-resolution data base and its environmental implications, J. Geophys. Res., 98, 1475314770, 1993.

Körner, U. and Sonnemann, G. R.: Global 3-D-modeling of water vapor concentration of the mesosphere/mesopause region and implications with respect to the NLC region, J. Geophys. Res., 106, 9639-9651, 2001.

Kremp, C., Berger, U., Hoffmann, P., Keuer, D., and Sonnemann, G. R.: Seasonal variation of middle latitude wind fields of the mesopause region - a comparison between observation and model calculation, Geophys. Res. Lett., 26, 1279-1282, 1999.

Lübken, F.-J.: Seasonal variation of turbulent energy dissipation rates at high latitudes as determined by in situ measurements of neutral density fluctuations, J. Geophys. Res., 102, 1344113456, 1997.

Lübken, F.-J.: No long term change of the thermal structure in the mesosphere at high latitudes during summer, Adv. Space Res., 28(7), 947-953, 2001.

Lübken, F.-J., Fricke, K.-H., and Langer, M.: Noctilucent clouds and the thermal structure near the Arctic mesopause, J. Geophys. Res., 101, 9489-9508, 1996.

Nedoluha, G. E. and Hartogh, P.: Upper stratosphere comparison (WVMS and WASPAM), in: Stratospheric and Their Role in Climate (A Project of the WMO/ICSU/IOC World Climate Research Program): SPARC Assessment of Upper Tropospheric and Stratospheric Water Vapor, edited by: Kley, D., Russell III, J. M., and Phillips, WMO/TD World Meteorol. Org., Geneva, Switzerland, 1043, 139-141,2000.

Nicolet, M.: Ozone and hydrogen reactions, Ann. Geophys., 26, 531,1970

Offermann, D. and Gerndt, R.: Upper mesospheric temperatures from $\mathrm{OH}^{*}$ emissions, in CIRA 1986, Part II, edited by: Rees, D., Barnett, J. J., and Labitzke, K., Adv. Space Res., 10(12), 217221, 1990.

Oldmans, S. J. and Hofmann, D. J.: Increase in lower stratospheric water vapour and a midlatitude northern hemisphere site from 1981-1994, Nature, 374, 146-149, 1995.

Röth, E.-P.: Fast algorithm to calculate the photon flux in optically dense media for use in photochemical models, Ber. BunsenGesellsch., Phys. Chem., 96, 417-420, 1994.

Sander, S. P., Friedl, R. R., Golden, D. M., Kurylo, M. J., Huie, R. E., Orkin, V. L., Moortgat, G. K., Wine, P. H., Ravishankara, A. R., Kolb, C. E., Molina, M. J., and Finlayson-Pitts, B. J.: Chemical kinetics and photochemical data for use in stratospheric modeling, JPL Publication 06-2, Evaluation Number 15, California Insitute of Technology, Pasadena, California, USA, 2006.

Schröder, W.: Were noctilucent clouds caused by the Krakatoa eruption?, B. Am. Meteor. Soc., 112, 2081-2085, 1999.

Seele, C. P. and Hartogh, P.: Water vapor of the polar middle atmosphere: Annual variation and summer mesospheric conditions as observed by ground-based microwave spectroscopy, Geophys. Res. Lett., 26, 1517-1529, 1999.

Shimazaki, T.: Minor Constituents in the Middle Atmosphere, D. Reidel, Norwell, Mass., USA, 444 pp., 1985.

Simon, P. C.: Solar irradiance between 120 and $400 \mathrm{~nm}$ and its variation, Sol. Phys., 74, 273-291, 1981.

Siskind, D. E., Connor, B.J., Eckman, R. S., Remsberg, E. E., Tsou, J. J., Parrish, A.: An intercomparison of model ozone deficits in the upper stratosphere and mesosphere from two data sets, J.
Geophys. Res., 100, 11191-11201, 1995.

Sonnemann, G. and Fichtelmann, B.: Enforced oscillations and resonances due to internal non-linear processes of photochemical systems in the atmosphere, Acta Geo. Geophys. Mont. Hung., 22, 301-311, 1987.

Sonnemann, G. and Fichtelmann, B.: Subharmonics, cascades of period doubling, and chaotic behavior of photochemistry of the mesopause region, J. Geophys. Res., 102, 1193-1203, 1997.

Sonnemann, G. R. and Körner, U.: The total hydrogen mixing ratio anomaly around the mesopause region, J. Geophys. Res., 108, 4692, doi:10.1029/2002JD003015, 2003.

Sonnemann, G. R. and Grygalashvyly, M.: Solar influence on mesospheric water vapor with impact on NLCs, J. Atmos. Sol. Terr. Phys., 67, 177-190, 2005a.

Sonnemann, G. R. and Grygalashvyly, M.: On the two-day oscillation and the day-to-day variability in global 3-D-modeling of the chemical system of the upper mesosphere/mesopause region, Nonlin. Proc. Geophys., 12, 691-705, 2005 b.

Sonnemann, G., Kremp, C., Ebel, A., and Berger, U.: A threedimensional dynamic model of minor constituents of the mesosphere, Atmos. Environ., 32, 3157-3172, 1998.

Sonnemann, G. R., Grygalashvyly, M., and Berger, U.: Autocatalytic water vapor production as a source of large mixing ratios within the middle to upper mesosphere, J. Geophys. Res., 110, D15303, doi:10.1029/2004JD005593, 2005a.

Sonnemann, G. R., Hartogh, P., and Grygalashvyly, M.: Nonlinear response of the ozone chemistry within the stratopause and mesopause region under realistic conditions, Proc. Int. Symp.: Topical Problems of Nonlinear Wave Physics NWP-2005, Nonlinear Phenomena in Environmental Research (NWP-3), 108109, St. Petersburg - Nizhny Novgorod, Russia, 2-9 August 2005 b.

Summers, M. E., Conway, R. R., Siskind, D. E., Bevilacqua, R., Strobel, D. F., and Zasadil, S.: Mesospheric $\mathrm{HO}_{\mathrm{x}}$ photochemistry: Constraints from recent satellite measurements of $\mathrm{OH}$ and $\mathrm{H}_{2} \mathrm{O}$, Geophys. Res. Lett., 23, 2097-2100, 1996.

Taubenheim, J., Entzian, G., and Berendorf, K.: Long-term decrease of mesospheric temperature, 1963-1995, inferred from radiowave reflection heights, Adv. Space Res., 20(11), 2059-2063, 1997.

Taylor, M. J.: A review of advances in imaging techniques for measuring short period gravity waves in the mesosphere and lower thermosphere, Adv. Space Res., 19, 667-676, 1997.

Taylor, M. J. and Garcia, F. J.: A two-dimensional spectral analysis of short period gravity waves imaged in the OI $(557.7 \mathrm{~nm})$ and near infra red $\mathrm{OH}$ nightglow emissions over Arecibo, Puerto Rico, Geophys. Res. Lett., 22, 2473-2476, 1995.

Taylor, M. J., Seo, S. H., Nakamura, T., Tsuda, T., Fukunishi, H., and Takahashi, Y.: Long base-line measurements of short-period mesospheric gravity waves during the SEEK campaign, Geophys. Res. Lett., 25, 1797-1800, 1998.

Thomas, G. E., Olivero, J. J., Jensen, E. J., Schröder, W., and Toon, O. B.: Relation between increasing methane and the presence of ice clouds at the mesopause, Nature, 338, 490-492, 1989.

Thomas, G. E. and Olivero, J.: Noctilucent clouds as possible indicators of global change in the mesosphere, Adv. Space Res., 28(7), 937-946, 2001.

Vidal-Madjar, A.: Evolution of the solar Lyman alpha flux during four consecutive years, Sol. Phys., 40, 69-86, 1975. 
Vidal-Madjar, A.: The solar spectrum at Lyman-alpha $1216 \AA$, in: The Solar Output and its Variation, edited by: White, O. R., Colo. Assoc. Univ. Press, Boulder, CA, USA, 213-236, 1977.

Vidal-Madjar, A. and Phissamay, B.: The solar L $\alpha$ flux near solar minimum, Sol. Phys., 66, 227-271, 1980.

von Zahn, U. and Berger, U.: The altitude of noctilucent clouds: Groundbased observations and their interpretation through numerical modeling, in Proceedings of the 16th ESA Symposium on European Rocket and Balloon Programmes and Related Research, St. Gallen, Switzerland, ESA SP-530, edited by: Warmbein, B., 295-301, 2003.
Walcek, C. J.: Minor flux adjustment near mixing ratio extremes for simplified yet highly accurate monotonic calculation of tracer advection, J. Geophys. Res., 105, 9335-9348, 2000.

Woods, T. N., Tobiska, W. K., Rottman, G. J., and Worden, J. R.: Improved solar Lyman $\alpha$ irradiance modeling from 1947 through 1999 based on UARS observations, J. Geophys. Res., 105, 27195-27215, 2000.

World Meteorological Organization (WMO), Scientific Assessment of Ozone Depletion: 1998, Geneva, Switzerland, 1999.

Yang, P. and Brasseur, G.: Dynamics of the oxygen-hydrogen system in the mesosphere, 1 . Photochemical equilibria and catastrophe, J. Geophys. Res., 99, 20955-20965, 1994. 